\title{
Application of Pyrite and Chalcopyrite Electrodes for the Acid-Base Determinations in Nitriles
}

\author{
Zoran Simić, ${ }^{a}$ Zorka D. Stanić*,a and Milan Antonijevic ${ }^{b}$ \\ ${ }^{a}$ Department of Chemistry, Faculty of Science, University of Kragujevac, R. Domanović 12, \\ P.O. Box 60, 34000 Kragujevac, Serbia \\ ${ }^{b}$ Technical Faculty Bor, University of Belgrade, 19210 BOR, Belgrade, Serbia
}

\begin{abstract}
Os minerais naturais pirita e chalcopirita tem sido usados como sensores em eletrodos indicadores usando acetronitrila e propionitrila como solventes. Os resultados mostram vantagens excepcionais da pirita e chacopirita como sensores eletroquímicos e também a possibilidade de aplicação desses eletrodos para determinações em solventes não aquosos onde eletrodos de vidro mostram dificuldades. O comportamento dos eletrodos indicadores de pirita e chalcopirita em nitrila foi avaliado pela titulação de diversas bases e ácidos de forças diferentes usando prótons e íons liato gerados pela oxidação de alguns ésteres de ácido gálico e fenóis diidróxi, bem como $m$-cresol e 3-metóxifenol. Os resultados obtidos com esses eletrodos foram comparados com os de eletrodos de vidro nas mesmas condições, obtendo-se boa concordância, reprodutividade e precisão. Os desvios padrão na determinação dos ácidos e bases investigados foram menores do que $0,9 \%$. Em titulações potenciométricas com pirita e chalcopirita como eletrodos indicadores, o potencial é instantaneamente estabelecido. Ambos os eletrodos podem ser usados sem qualquer limitação temporal ou divergências potenciais consideráveis.
\end{abstract}

The natural minerals pyrite and chalcopyrite have been used as the indicator electrode sensors using acetonitrile and propionitrile as solvents. The results show the exceptional advantage of pyrite and chalcopyrite as electrochemical sensors and also the possibility of the application of these electrodes for the determination in nonaqueous solutions where glass electrode shows many defaults. The behaviour of the pyrite and chalcopyrite indicator electrodes in nitriles were checked by titrating several bases and acids of different strengths using protons and lyate ions generated by the oxidation of some gallic acid esters and dihydroxy phenols, as well as $m$-cresol and 3-metoxy phenol. The results obtained by using these electrodes were compared with those obtained by the application of a glass electrode under the same conditions, and good agreement, reproducibility and accuracy were obtained. The standard deviation of the determination of the investigated acids and bases was less than $0.9 \%$. In the potentiometric titrations with pyrite and chalcopyrite indicator electrodes, the potential is instantaneously established throughout. Both electrodes can be used without any time limit or without considerable divergence in potentials.

Keywords: pyrite, chalcopyrite, hydrogen and lyate ions, nonaqueous solutions

\section{Introduction}

Low molecular weight nitrides, as solvents from the dipolar aprotic solvents (DAS) group, have been very successfully applied in electrochemical investigations as they are chemically inert, and can be oxidized and reduced only with difficulty. From this group of solvents, acetonitrile was found the widest application, whereas other nitriles, such as propionitrile, butionitrile and

\footnotetext{
*e-mail: zorkas@kg.ac.rs
}

benzonitrile, have been used more rarely. Although the above-mentioned solvents possess all properties of a good solvent for electrochemical investigations, only a few data (with the exception of acetonitrile) on their use in acid-base determinations have been reported. ${ }^{1}$

Using coulometric methods for the determination of acids and bases and owing to the electrochemically obtained titrant with a high current efficiency, it is possible to analyze solutions of low concentrations and to determine accurately and reproducibly small amounts of substances. In the course of the coulometric determinations of bases in 
non-aqueous solvents, the electrochemical generation of hydrogen ions is realized by the oxidation of an appropriate electroreactive compounds (anodic depolarizers). Previously, the generation of hydrogen ions was performed quantitatively by the oxidation of hydroquinone and thus a new field of investigation, ${ }^{1}$ with the application of some other compounds of low oxidation potentials, was opened. Some authors, ${ }^{2-5}$ have applied a whole range of organic compounds, mercury and hydrogen dissolved in palladium as the medium for the generation of $\mathrm{H}^{+}$ions in the coulometric titrations of bases with visual, photometric and potentiometric end point determination. For the titration of bases in some aprotic solvents, instead of a standard solution of perchloric acid that is unstable in these solvents, Mihajlovic et al..$^{6}$ used hydrogen ions generated by the electro-oxidation of some organic depolarizers at a platinum anode. It was emphasized that the application hydrogen or deuterium dissolved in palladium have advantages over many classical depolarizers because no foreign substances are introduced into the solution being

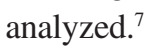

As the medium for the catholic generation of lyate ions in the coulometric determinations of acids, some alcohols, $m$-cresol and dimethylsulfoxide were used. ${ }^{8-10}$ Under the certain conditions, a reduction of the above-mentioned compounds is performed, whereby a hydrogen is separated at a platinum cathode and lyate ions are generated with a high percentage current efficiency. With the use of this method, many weak organic acids were determined. In organic acids coulometric determination, bases were generated in a solution of some organic salts or tetraethylammonium halogenide. Streuli et al. ${ }^{11}$ coulometrically titrated benzoic acid in acetone using tetraethyl-ammonium bromide and tetraethyl-ammonium perchlorate as the supporting electrolyte and generated hydroxide ions by the reduction of water, which was added to the solution up to a concentration of $1 \%(\mathrm{~m} / \mathrm{v})$. Fritz and Gainer ${ }^{12}$ titrated acids by generating the base in $t$-butanol, while Johansson ${ }^{13}$ generated the base in 2-propanol, and a mixture of 2-propanol and methyl acetone as solvents.

For more than 60 years, $\mathrm{pH}$-glass electrodes have been widely used, and $\mathrm{pH}$ measurements in various samples are still made using these electrodes. They are very popular due to their high selectivity and dynamic $\mathrm{pH}$ range. However, in spite of the distinctive potential characteristic of $\mathrm{pH}$-glass electrodes and their use in routine $\mathrm{pH}$ measurements for so many years, they have certain limitations, such as high resistance, brittleness, instability in hydrofluoric acid and in fluoride-containing media as well as in nonaqueous solutions. They are also challenging in the construction of microelectrodes for biological applications and in vivo measurements. That is why studies related to the construction of nonglass $\mathrm{pH}$ electrodes have been gaining momentum. The construction of $\mathrm{pH}$ electrodes based on neutral carriers will solve most of these problems. While developing alternative possibilities for the $\mathrm{H}^{+}$ions determination during acid-base titrations, many authors investigated applications of a metal and metalloid electrodes, ${ }^{14,15}$ metal oxide electrodes, ${ }^{16-18}$ monocrystalline sulphide electrodes. ${ }^{19-22}$ Sulphide minerals (pyrite, chalcopyrite and galena) have been investigated as indicator electrodes for acid-base $e^{23,24}$ and redox titration in some non-aqueous solvents. The anodic dissolution process of chalcopyrite using various auxiliary analytical methods for the identification of the reaction products ${ }^{25,26}$ and the cathodic reduction of chalcopyrite ${ }^{27}$ have been investigated by different authors. Antonijevic et al..$^{28}$ used natural monocrystalline chalcopyrite for potentiometric titration in water. Mihajlovic et al. ${ }^{23,29}$ used natural monocrystalline chalcopyrite for potentiometric acid-base and redox titration in some nonaqueous solutions. The facts that all of these natural monocrystallines have low electrical resistance and that they are easy to construct have increased interest in the implementation of these electrodes in place of glass membranes. These electrodes are of great practical importance, since they are solid and unbreakable.

Proceeding from the fact that acetonitrile and propionitrile are good solvents for electrochemical acidbase investigations, in this work, propionitrile was applied for the coulometric determination of bases with hydrogen ions generated by the oxidation of anode depolarizers (dihydroxy, trihydroxy phenols, and some of esters of gallic acid). The $m$-cresol and 3-methoxy phenol we used in acetonitrile and propionitrile as cathodic depolarizers and as the medium for the generation of lyate ions in the coulometric determination of acids. No data are reported in the literature on its application for coulometric generation lyate ions in these solvents. For the potentiometric detection of the end point, monocrystalline pyrite $\left(\mathrm{FeS}_{2}\right)$ and chalcopyrite $\left(\mathrm{CuFeS}_{2}\right)$ were used and the results compared with those obtained with a glass electrode.

\section{Experimental}

\section{Reagents}

All the investigated depolarizers and titrated bases were of p.a. purity, Merck or Fluka. Before use, the liquid bases were dried over fused potassium hydroxide and then distilled under reduced pressure. The concentration of the solutions of bases was checked by titration with $\mathrm{H}^{+}$ions generated by the oxidation of hydrogen dissolved in palladium. All the employed acids were of p.a. purity, Merck and Fluka. Before use, the acids were standardized 
with tetraethylammonium hydroxide (TBAH) in methanol. Acetonitrile and propionitrile were purified before use by a procedure described in the literature. ${ }^{30,31}$ As the conducting salt in acetonitrile and propionitrile for coulometric determination of bases, a $0.25 \mathrm{~mol} \mathrm{~L}^{-1}$ solution of sodium perchlorate was used. As the conducting salt in solvents for coulometric determination of acids, a $0.1 \mathrm{~mol} \mathrm{~L}^{-1}$ tetrabutylammonium perchlorate was used.

\section{Apparatus and electrodes}

The apparatus employed for the coulometric titration of bases was described previously. ${ }^{7}$ The current source was a voltage and current stabilizer. The anode and cathode compartments were separated by a G-4 sintered glass disc. The volume of the investigated solution was $20.00 \mathrm{~mL}$ and that of the catholyte $5.00 \mathrm{~mL}$. Platinum spirals of surface area $25 \mathrm{~mm}^{2}$ were used as the anode and cathode.

A conventional glass electrode (G 200 B, Radiometer) was used as the indicator electrode and a modified saturated calomel electrode (401 Radiometer, Copenhagen) was used as the reference electrode. The modification of the normal SCE has been done by complete replacement of the inner solution with the saturated solution of potassium chloride in corresponding solvent. This modification has been done to decrease the liquid junction potential between inner solution of the SCE and investigated solution. The glass electrode was conditioned in the appropriate solvent $48 \mathrm{~h}$ before use.

The experiments were carried out with either a sample of natural pyrite or a chalcopyrite crystal from the Veliki Krivelj copper mine (Bor, Serbia). Chemical analyses of the minerals showed that the pyrite contained $44.3 \% \mathrm{Fe}$, $52.5 \% \mathrm{~S}$, and $0.6 \% \mathrm{Cu}$ and the chalcopyrite $27.1 \% \mathrm{Fe}$, $34.2 \% \mathrm{~S}$, and $33.2 \% \mathrm{Cu}$.

The indicator chalcopyrite electrode was prepared in the following manner: ${ }^{23} \mathrm{~A}$ quadratic piece of chalcopyrite $(a=0.5$ $\mathrm{cm})$ was used as the electrode material. The chalcopyrite electrode was made by polishing the chalcopyrite crystal with diamond paste, and the best polished side was used as the working surface of the electrode. A narrow glass tube was fixed with glue to the other side of the electrode and then filled with mercury. One end of a copper wire was immersed in the mercury and this device was mounted into a wider glass tube $(\varnothing=1 \mathrm{~cm})$ which was then cemented with a cold sealing mass based on methyl methacrylate. After solidification of this mass, the working surface of electrode was polished to a high glow. The electrode was then rinsed with distilled water and alcohol, and dried on air after which it was ready for use. A pyrite indicator electrode was prepared in a similar way. The pyrite and chalcopyrite electrodes were made by polishing a pyrite (chalcopyrite) crystal with $\mathrm{Al}_{2} \mathrm{O}_{3}$ and the best polished was used as the working surface of the electrode.

The potential was measured during the titration by means of a "Iskra" pH meter MA 5740. The currentpotential curves (anode and cathode) were recorded on a Polarographic analyzer PA2.

\section{Potentiometric measurements}

Stationary potential measurements of the electrodes were carried out in a series of $p$-toluenesulfonic acid in the concentration range of $0.1-0.001 \mathrm{~mol} \mathrm{~L}^{-1}$. The potential of the pyrite (chalcopyrite) electrode with time was followed in a temperature-controlled cell $\left(25 \pm 0.1^{\circ} \mathrm{C}\right)$. The ionic strength of the solution was maintained with $0.05 \mathrm{~mol} \mathrm{~L}^{-1}$ tetrabutylammonium perchlorate. The potential values determined in this way were used to calculate of the slopes. The change in the potential of the pyrite (chalcopyrite) electrode with time was followed in the required solvent. This indicator electrode was coupled with a modified SCE as the reference electrode.

\section{Potentiometric end point detection}

The supporting electrolyte was added to a certain level into the cathode compartment of the vessel and a platinum spiral was immersed in it; a titrated supporting electrolyte solution was poured into the anode compartment up to the same level and the depolarizer was added. A Pt anode and an electrode couple (glass-SCE, $\mathrm{CuFeS}_{2}-\mathrm{SCE}, \mathrm{FeS}_{2}-\mathrm{SCE}$ ) were immersed in the investigated solution. During the determination of acids, the investigated acid was added into the cathode compartment and after the current was switched on, lyate ions were generated. The solution was vigorously stirred with a magnetic stirrer during the titration. The potential was measured after each addition of lyate ions, at 2-3 min interval. The end point was determined by the classical method from the second derivative or the Gran method. ${ }^{32}$ Several samples can be determined successively in the same supporting electrolyte.

The procedure for the determination of bases was the same as for the determination of acids, except the generation of acids (hydrogen ions) was performed in the anode compartment of the electrolysis vessel.

\section{Results and Discussion}

\section{Mechanism of the indicator pyrite (chalcopyrite) electrode}

Pyrite and chalcopyrite are sensors which potential depends on many factors: the nature of the oxidant, the 
$\mathrm{pH}$ value, the temperature, the nature and concentration of the present cations, anions and other chemical species.

The electronic structure of pyrite indicates its low-spin complex with $\mathrm{d}^{2} \mathrm{sp}^{3}$ hybridization. The hybrid orbitals are occupied with electrons, which makes pyrite a nonreactive compound. Pyrite, $\mathrm{FeS}_{2}$, is a mineral that possesses characteristic electric and magnetic properties. It is sparingly soluble in water and it catalytically reduces oxygen present in the solution. The reduction of oxygen causes the anionic dissolution $\mathrm{FeS}_{2}$ to $\mathrm{Fe}^{2+}$ and $\mathrm{SO}_{4}{ }^{2-}$ following the equation: ${ }^{33}$

$\mathrm{FeS}_{2}+8 \mathrm{H}_{2} \mathrm{O} \rightarrow \mathrm{Fe}^{2+}+2 \mathrm{SO}_{4}^{2-}+16 \mathrm{H}^{+}+14 e^{-}$

$\mathrm{Fe}^{2+}$ ions in an oxidative environment are oxidized to $\mathrm{Fe}^{3+}$ ions. The hydrolysis of iron cations can be described by the following equation:

$\mathrm{Fe}^{n+}+2 \mathrm{kH}_{2} \mathrm{O} \rightarrow \mathrm{Fe}(\mathrm{OH})_{k}^{(n-k)+}+\mathrm{kH}_{3} \mathrm{O}^{+}$

The formation of hydroxide according to equation (2) forms a film on the surface of the pyrite crystals, which actually represents a hydroxysulfide/metal electrode $\left(\mathrm{Fe}(\mathrm{OH})_{k}^{(n-k)+} / \mathrm{FeS}_{2}\right)$, which potential is defined by the equation:

$E=E_{o x}^{o}+\frac{R T}{n F} \ln a_{H_{3} O^{+}}^{k}$

Equation (3) shows that the potential of the electrode depends on the activity of $\mathrm{H}^{+}$ions when used in both water and non-water environment that contains weak acids or bases.

Similar to pyrite, the mineral chalcopyrite, $\mathrm{CuFeS}$, is also sparingly soluble in water and can only be dissolved in the presence of strong oxidizing agents, thus generating products of different composition. The oxidation can be represented by the equations: ${ }^{34-38}$

$$
\begin{aligned}
& \mathrm{CuFeS}_{2}+8 \mathrm{H}_{2} \mathrm{O} \rightarrow \mathrm{Cu}^{2+}+\mathrm{Fe}^{3+}+2 \mathrm{SO}_{4}^{2-}+16 \mathrm{H}^{+}+17 e^{-} \\
& \mathrm{CuFeS}_{2}+4 \mathrm{H}^{+}+\mathrm{O}_{2} \rightarrow \mathrm{Cu}^{2+}+\mathrm{Fe}^{2+}+2 \mathrm{~S}^{o}+2 \mathrm{H}_{2} \mathrm{O} \\
& \mathrm{CuFeS}_{2}+4 \mathrm{O}_{2} \rightarrow \mathrm{Cu}^{2+}+\mathrm{Fe}^{2+}+2 \mathrm{SO}_{4}^{2-} \\
& 2 \mathrm{Fe}^{2+}+1 / 2 \mathrm{O}_{2}+2 \mathrm{H}^{+} \rightarrow 2 \mathrm{Fe}^{3+}+\mathrm{H}_{2} \mathrm{O} \\
& \mathrm{CuFeS}_{2}+3 \mathrm{OH}^{-} \rightarrow \mathrm{CuS}_{2}+\mathrm{Fe}(\mathrm{OH})_{3}+3 e^{-} \\
& 2 \mathrm{CuFeS}_{2}+6 \mathrm{OH}^{-} \rightarrow 2 \mathrm{CuS}_{2}+\mathrm{Fe}_{2} \mathrm{O}_{3}+3 \mathrm{H}_{2} \mathrm{O}+6 e^{-}
\end{aligned}
$$

From these equations, in addition to elementary sulfur and sulfates, $\mathrm{Fe}^{2+}, \mathrm{Fe}^{3+}$ and $\mathrm{Cu}^{2+}$ cations are also products of the oxidation, which hydrolyze. As iron cations are hydrolyzed at lower $\mathrm{pH}$ values than copper ones, only the hydrolysis of iron cations will be considered in the further text. The hydrolyzed iron cations influence the formation of a hydroxysulfide / metal layer, $\mathrm{Fe}(\mathrm{OH})_{k}^{(n-k)+} / \mathrm{CuFeS}$, on the surface of the $\mathrm{CuFeS}_{2}$ crystals. This layer actually represents an electrode the potential of which is described by equation (3) for both an aqueous and non-aqueous environment.

\section{Characteristics of the indicator pyrite (chalcopyrite) electrode}

In order to apply an ion selective electrode as a sensor for use in quantitative measurements, a stable potential in both acid and base environments, a relatively short response time, and a long life-time must be ensured.

\section{Potential of the electrodes}

The stationary potential of a pyrite and a chalcopyrite electrode in acetonitrile and propionitrile was measured by direct potentiometry at $25 \pm 0.1^{\circ} \mathrm{C}$ in a freshly prepared $0.05 \mathrm{~mol} \mathrm{~L}^{-1}$ solution of $p$-toluenesulfonic acid in the appropriate solvents. All measurements were performed in the presence of a background electrolyte of constant ionic strength $\left(0.05 \mathrm{~mol} \mathrm{~L}^{-1}\right.$ tetrabutylammonium perchlorate) in order to minimize the effect of streaming and diffusion potentials in the streaming sample solution. In the both of the investigated solutions, a stable potential was attained in less than 4-5 min.

\section{Slope of the potential response of the electrodes}

The potential of the electrodes were determined using a series of $p$-toluenesulfonic acid in the concentration range of 0.1-0.001 mol L-1 in acetonitrile and propionitrile in a temperature-controlled cell $\left(25 \pm 0.1^{\circ} \mathrm{C}\right)$. The ionic strength of the solutions was maintained with $0.05 \mathrm{~mol} \mathrm{~L}^{-1}$ tetrabutylammonium perchlorate. It was found that the electrodes show sub-Nernst dependence. Since the electrodes exhibit sub-Nernst dependence, those cannot be used for measuring the $\mathrm{pH}$ of a solution. However, the potential of the electrodes as indicator electrodes are very stable with respect to time: hence, those can be successfully applied to the titration of acids and bases in acetonitrile and propionitrile as the solvents.

\section{Response time of the electrodes}

The response time of a pyrite and a chalcopyrite electrode was determined by recording the time elapsed before a stable potential value was attained after the pyrite (chalcopyrite) electrode and the reference electrode (modified SCE) were immersed in calibration solutions 
Table 1. Potential jumps $(\mathrm{mV})$ at the end-point in the coulometric-potentiometric titrations of acids in acetonitrile and propionitrile

\begin{tabular}{llcc}
\hline Solvent & Titrated acid & glass-SCE & CuFeS $-\mathrm{SCE}$ \\
\hline Acetonitrile & p-Toluensulphonic & 155 & 158 \\
& 5-Sulphosalicylic & 135 & 130 \\
& Oxalic acid & 120 & 107 \\
Propionitrile & p-Toluensulphonic & 132 & 95 \\
& 5-Sulphosalicylic & 145 & 130 \\
& Oxalic acid & 120 & 75 \\
\hline
\end{tabular}

from highly acidic $\left(0.05 \mathrm{~mol} \mathrm{~L} \mathrm{~L}^{-1}\right.$ of $p$-toluenesulfonic acid) to highly basic (0.05 mol L-1 $\mathrm{TBAH})$ solutions. From the acidic ( $p$-toluenesulfonic acid) to the basic region (TBAH), the change of the electrode potential for the pyrite electrode ranged from -190 to $+415 \mathrm{mV}$ (acetonitrile) and for the chalcopyrite electrode ranged from -365 to +496 (acetonitrile). Therefore, the potential changes at the TEP (titration end point) for the chalcopyrite electrode were greater than those for the pyrite electrode (Table 1). The response time for the pyrite was $12 \mathrm{~s}$ and for the chalcopyrite electrode was $11 \mathrm{~s}$ in the investigated solvents.

\section{Long-term stability (lifetime) and repeatability}

The lifetime of the electrodes was determined by raising the potential values of the calibration solution ( $p$-toluenesulfonic acid) and plotting the calibration curves for a period of of 1 year. The slope of the electrodes remained constant. When the electrodes are not used for titrations, these are kept in a dry place protected from dust. Before the next use, the electrodes are kept in the investigated solvent for half an hour. However, if the electrodes had been used frequently and for a long time, it is necessary to rub the crystal pyrite (chalcopyrite) with aluminum oxide, wash the electrodes and continue with use.

In order to establish the efficiency of use of the electrodes in potentiometric titrations and the repeatability of the results obtained, the titration of $p$-toluenesulfonic acid (acetonitrile) was selected as a model and it was repetitively carried out for five times and the end point was monitored by using pyrite electrode. The results obtained for the titration $p$-toluenesulfonic acid (acetonitrile) were shown in Figure 1. The relative standard deviation (RSD) for the end point determination of titration was found to be $0.5 \%$ (Table 2 ).

\section{Coulometric-potentiometric determinations of acids using pyrite and chalcopyrite as indicator electrodes}

For the coulometric determination of acids, lyate ions can be generated either by direct cathodic reduction at

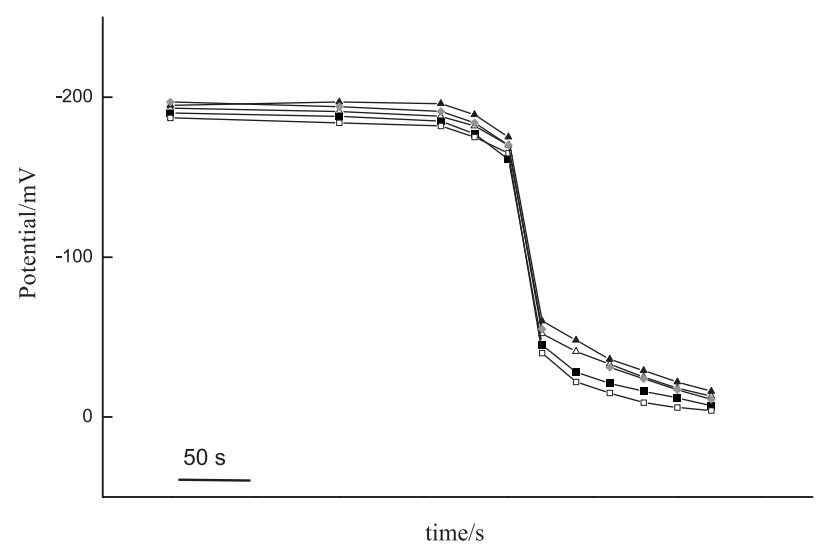

Figure 1. Five titration curves of $p$-toluenesulfonic acid in acetonitrile obtained by using $m$-cresole and pyrite as indicator electrode.

a platinum cathode or by the reduction of the solvents with a high current efficiency and by the reduction of suitable electroreactive compounds. The condition for the application of electroreactive compounds (cathodic depolarizer) in the solution is that they are reduced quantitatively before the reduction of the other components occurs. The first alkalimetric titrations in non-aqueous solvents employed a strong base as titrant that was obtained by the reduction of water at a platinum electrode. ${ }^{39}$

Tetrabutylammonium bromide and tetrabutylammonium perchlorate as the supporting electrolyte were used to generate hydroxide ions by the reduction of water, which had been added to the solution in a concentration of up to $1 \%(\mathrm{~m} / \mathrm{v}) .{ }^{40} \mathrm{Few}$ data in the literature report the application of organic compounds, which on reduction produce a strong base. Water can be used as a cathodic depolarizer (in concentrations of up to $0.5 \%(\mathrm{~m} / \mathrm{v})$ ), although it has an adverse effect on the conditions of the titration. In this study, a procedure was developed for the direct coulometric generation of strong bases by reduction of the organic compounds $m$-cresol and 3-methoxy phenol in nitrile media.

$m$-Cresol and 3-methoxy phenol are reduced with ease and the equivalent amount of lyate ions separate at the platinum cathode. Such generated ions can be used as the strong bases for the determination of acids. The 
Table 2. Results of coulometric titrations of acids in acetonitrile and propionitrile with lyate ions obtained by the reduction of $m$-cresole, and 3-metoxy phenole with potentiometric end-point detection; $\mathrm{I}=5 \mathrm{~mA}$

\begin{tabular}{|c|c|c|c|c|}
\hline$\underline{\text { Solvent }}$ & Depolarizer & Titrated acid & Taken (mg) & Recovery $(\%)$ \\
\hline \multirow[t]{12}{*}{ Acetonitrile } & $m$-Cresole & $p$-Toluensulphonic & 8.75 & $100.3 \pm 0.3$ (a) \\
\hline & & & 8.75 & $99.1 \pm 0.5$ (b) \\
\hline & & & 8.75 & $98.7 \pm 0.7(\mathrm{c})$ \\
\hline & & 5-Suphosalicylic & 11.54 & $100.9 \pm 0.2$ (a) \\
\hline & & & 11.54 & $100.7 \pm 0.9(b)$ \\
\hline & & & 11.54 & $98.8 \pm 0.5(\mathrm{c})$ \\
\hline & & Trichloracetic & 10.29 & $99.5 \pm 0.4$ (a) \\
\hline & & & 10.29 & $99.1 \pm 0.9$ (b) \\
\hline & & & 10.29 & $101.3 \pm 0.6(\mathrm{c})$ \\
\hline & & Oxalic acid & 9.24 & $99.6 \pm 0.5$ (a) \\
\hline & & & 9.24 & $100.7 \pm 0.7(b)$ \\
\hline & & & 9.24 & $98.6 \pm 0.5(\mathrm{c})$ \\
\hline \multirow[t]{12}{*}{ Propionitrile } & 3-Metoxy phenole & $p$-Toluensulphonic & 7.31 & $100.6 \pm 0.8$ (a) \\
\hline & & & 7.31 & $101.8 \pm 0.9(\mathrm{~b})$ \\
\hline & & & 7.31 & $100.4 \pm 0.8(\mathrm{c})$ \\
\hline & & 5-Suphosalicylic & 9.67 & $98.7 \pm 0.6$ (a) \\
\hline & & & 9.67 & $101.8 \pm 0.9(b)$ \\
\hline & & & 9.67 & $99.4 \pm 0.8(\mathrm{c})$ \\
\hline & & Trichloracetic & 8.13 & $100.7 \pm 0.8$ (a) \\
\hline & & & 8.13 & $98.4 \pm 0.8(b)$ \\
\hline & & & 8.13 & $98.4 \pm 0.7(\mathrm{c})$ \\
\hline & & Oxalic acid & 6.82 & $101.5 \pm 0.7$ (a) \\
\hline & & & 6.82 & $99.6 \pm 0.4(b)$ \\
\hline & & & 6.82 & $98.9 \pm 0.6(\mathrm{c})$ \\
\hline
\end{tabular}

(a) Glass-SCE; (b) $\mathrm{FeS}_{2}$-SCE; (c) $\mathrm{CuFeS}_{2}$-SCE.

reduction of $m$-cresole and 3-metoxy phenole according to the equations:

$2 \mathrm{C}_{6} \mathrm{H}_{4}\left(\mathrm{CH}_{3}\right) \mathrm{OH}+2 e^{-} \rightarrow \mathrm{H}_{2}+2 \mathrm{C}_{6} \mathrm{H}_{4}\left(\mathrm{CH}_{3}\right) \mathrm{O}^{-}$

$2 \mathrm{C}_{6} \mathrm{H}_{4}\left(\mathrm{OCH}_{3}\right) \mathrm{OH}+2 e^{-} \rightarrow \mathrm{H}_{2}+2 \mathrm{C}_{6} \mathrm{H}_{4}\left(\mathrm{OCH}_{3}\right) \mathrm{O}^{-}$

In order to establish the approximate potentials of the reduction of the components of the employed system of nitrile-0.05 mol L-1 TBAP (tetrabutylammonium perchlorate), voltametric curves were recorded under the same conditions as those used for the determination of the acids (Figure 2). From the figure, it can be seen that $m$-cresol is reduced in acetonitrile at a potential of about $-0.9 \mathrm{~V}$, which is about $0.7 \mathrm{~V}$ more positive than the reduction potential of the other components. $p$-Toluenesulfonic, trichloracetic, oxalic and 5-sulfosalicylic acids were titrated with $m$-cresol ions generated at the cathode. Also, on the basis of its structure, it would be expected that, like

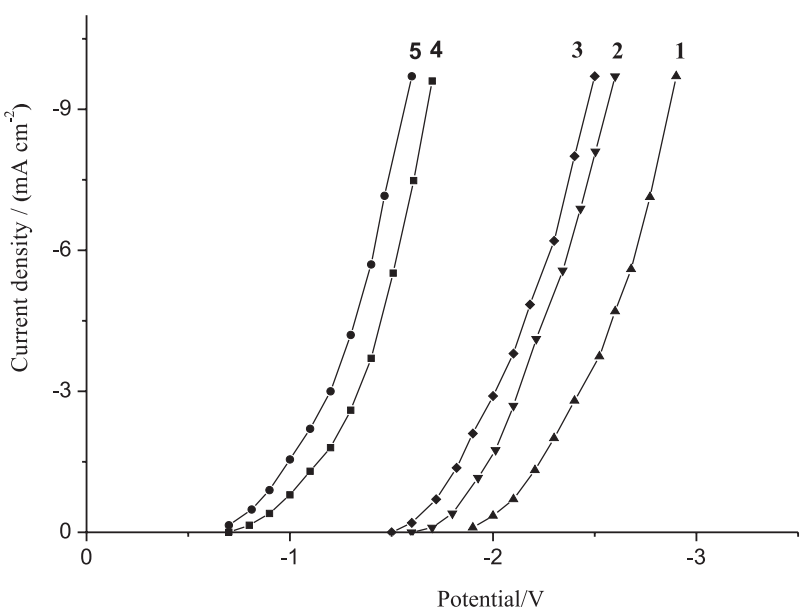

Figure 2. Change in cathodic potential with current density in acetonitrile: 1) solvent; 2) trichloracetic acid; 3) 5-sulphosalicylic acid; 4) 3-metoxy phenole; 5) $m$-cresole.

$m$-cresol, 3-methoxy phenol would be reduced and generate an equivalent amount of lyate ions. Current-potential curves 
recorded for 3-methoxy phenol, acetonitrile, and the titrated acids showed that the reduction potential of 3-methoxy phenol was higher than those of the other components in the solutions (Figure 2). Accordingly, it can be seen that $m$-cresol and 3-methoxy phenol were reduced at a much more positive potential than those of the titrated acids and solvent used; thus, the condition for the application of these compounds as a cathodic depolarizers is satisfied.

The results of the determinations of 20-100 milliequivalent of acid are shown in Table 2. The end point detection was performed potentiometrically with a glass electrode, a pyrite and a chalcopyrite as the indicator electrodes and with a modified saturated calomel electrode as the reference. The results given in the Table show that the current efficiency was within 98.4-101.8\%, with a good reproducibility.

The titration curves of $p$-toluenesulfonic, trichloracetic, oxalic, and 5-sulfosalicylic acids in acetonitrile and propionitrile with the application of the electrode couples $\mathrm{FeS}_{2}$-SCE and $\mathrm{CuFeS}_{2}$-SCE are shown in Figures 3 and 4. In the coulometric titration of, for example, $p$-toluenesulfonic acid with the application of the $\mathrm{FeS}_{2}-\mathrm{SCE}$ electrode pair, the rise of potential at the EP was $118 \mathrm{mV}$, whereas under the same conditions but applying the $\mathrm{CuFeS}$-SCE electrode pair, the rise of the potential at the EP was $158 \mathrm{mV}$ (Table 1). Using a glass indicator electrode under all conditions, a slightly higher increase of potential $(155 \mathrm{mV})$ was obtained at the EP. In propionitrile as the solvent, using coulometrically generated lyate ions for the titration of the same acid, the increase in the potential at the EP was $75 \mathrm{mV}$ and $95 \mathrm{mV}$ for the electrode pairs $\mathrm{FeS}_{2}$-SCE and $\mathrm{CuFeS}$-SCE, respectively. As in the previous case, a higher increase of the potential was achieved by application of the glass electrode during the titration of the above mentioned acid (Table 1). Using propionitrile as solvent, with the $\mathrm{FeS}_{2}$ electrode as the indicator electrode, the rises of the potential

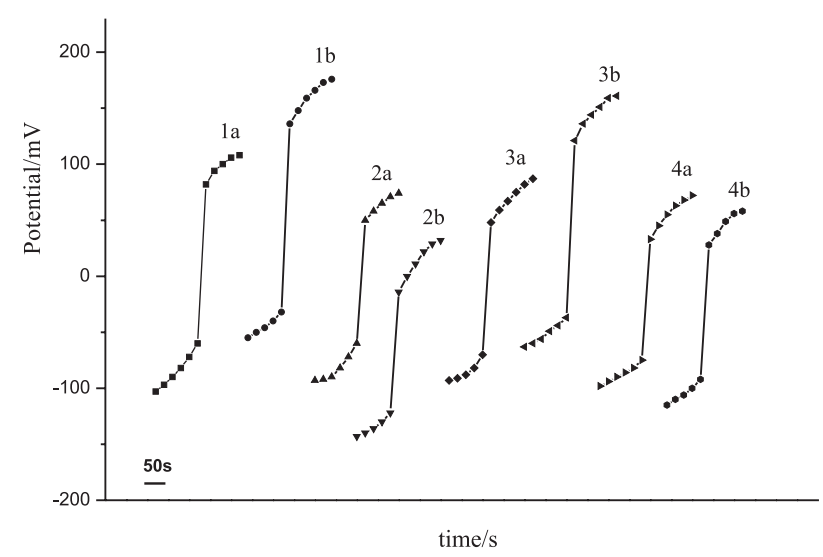

Figure 3. The effect of the indicator electrode on the shape of the end-point inflection in the coulometric-potentiometric titration of acids in acetonitrile by using $m$-cresole: a) $\mathrm{FeS}_{2}-\mathrm{SCE}$; b) $\mathrm{CuFeS}_{2}-\mathrm{SCE}$; 1$)$ trichloracetic; 2) oxalic; 3) $p$-toluenesulfonic; 4) 5-sulfosalicylic acid; I = $5 \mathrm{~mA}$.

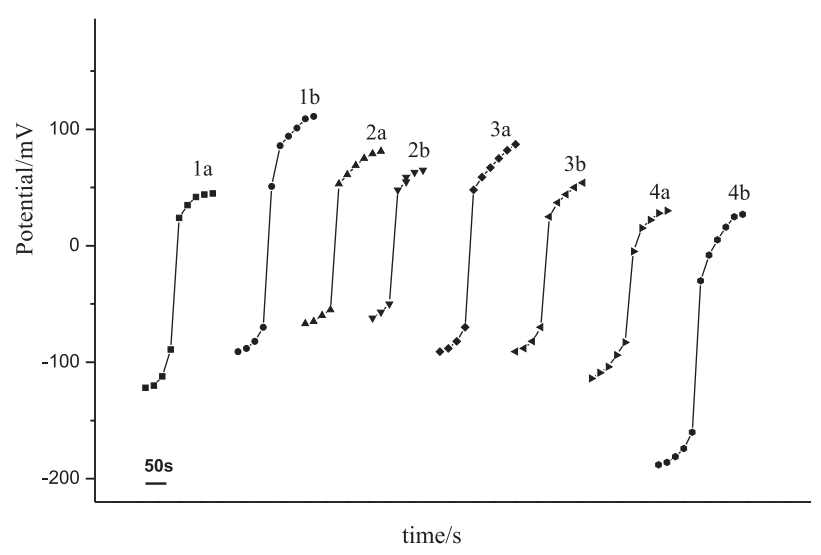

Figure 4. The effect of the indicator electrode on the shape of the endpoint inflection in the coulometric-potentiometric titration of acids in propionitrile by using 3-metoxy phenole: a) $\mathrm{FeS}_{2}-\mathrm{SCE}$; b) $\mathrm{CuFeS}_{2}-\mathrm{SCE}$; 1) trichloracetic; 2) oxalic; 3) p-toluenesulfonic; 4) 5-sulfosalicylic acid; $\mathrm{I}=5 \mathrm{~mA}$.

at the EP were slightly higher compared to those obtained using the $\mathrm{CuFeS}$ electrode. Also, Table 1 shows that in all cases in which the sulfide electrodes were employed, the increases of the potential at the EP were slightly smaller when compared those obtained using a glass electrode. Although the highest potential jumps were obtained with the glass electrode, a glass electrode has a limited useful life because organic solvents dehydrate its membrane. On the other hand, the potential during the titration was very stable and rapidly established when the sulfide electrodes $\left(\mathrm{FeS}_{2}\right.$ and $\mathrm{CuFeS}$ ) were applied.

Coulometric-potentiometric determinations of bases using pyrite and chalcopyrite as indicator electrodes

Dipolar aprotic solvents affect not only the solubility of substances and their acid-base properties but they also enlarge and extend significantly the potential region for possible measurements. For this reason, these solvents can be used more successfully as a medium for the investigations of numerous compounds than water. Under certain conditions, some suitable electroreactive compounds are oxidized quantitatively with the generation of acids $\left(\mathrm{H}^{+}\right.$ions $)$in the propionitrile as solvent at the positively polarized platinum anode.

In previous studies, it was demonstrated that $\mathrm{H}^{+}$ions can be generated by the oxidation of hydrogen dissolved in palladium and also by the oxidation of some organic compounds with a low oxidation potential. ${ }^{3,6,41-45}$ Some dihydroxy and trihydroxy phenols and some esters of gallic acid can be applied for the coulometric generation of acids (hydrogen ions) in some dipolar aprotic solvents, such as acetonitrile, acetic acid-acetic anhydride, nitromethane, sulfolane and $\gamma$-butyrolactone. ${ }^{6,41}$ As propionitrile is a 
good solvent and as the literature contains little data on its application to coulometric determinations, it was considered of interest to investigate the possibility of applying $m$-dihydroxy benzene and some gallic acid esters for the coulometric generation of acid. These depolarizers have low oxidation potentials, much lower than those of other components present.

In order to establish whether the used compounds could be applied for the generation of acids in the investigated solvent, IE curves for the solvents, bases, indicators and anode depolarizers were recorded (Figure 5). The IE curves were recorded under the same conditions as those employed for the coulometric-potentiometric determination of bases. The employed compound oxidized at potentials about $0.2-0.8 \mathrm{~V}$ lower than the potential of the other components present in the solution. The difference between the oxidation potential of the depolarizer and those of the other compounds in the solution depends on the nature of the solvent and the depolarizer. When, in the course of coulometric titrations, the current is switched on, oxidation of the depolarizers occurs first, i.e., acid is generated, and oxidation of other components does not occur until there is a sufficient volume of the depolarizer. The oxidation esters of gallic acid according to the equation:

$$
(\mathrm{COOR}) \mathrm{C}_{6} \mathrm{H}_{2}(\mathrm{OH})_{3} \rightarrow(\mathrm{COOR}) \mathrm{C}_{6} \mathrm{H}_{2} \mathrm{O}_{2}(\mathrm{OH})+2 \mathrm{H}^{+}+2 e^{-}
$$

In order to determine whether the acids are generated quantitatively under the given conditions, standard solutions of the bases were titrated with potentiometric end point detection using electrode pair $\mathrm{FeS}_{2}$-SCE. When the pyrite electrode was applied as the indicator electrode in acetonitrile and propionitrile as solvents, in the course of the titration the potential was established

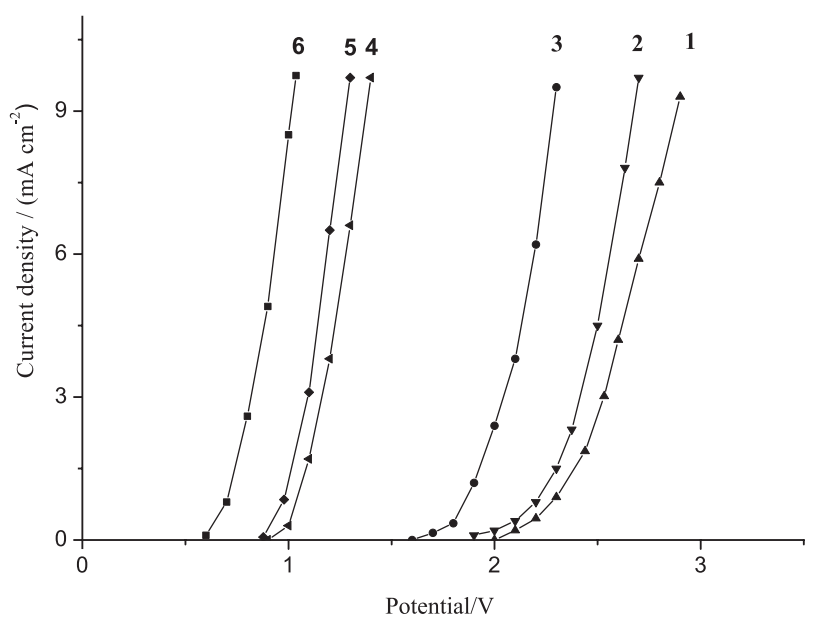

Figure 5. Change in anodic potential with current density in propionitrile: 1) solvent; 2) collidine; 3) 2,2 -bipyridine; 4) dodecyl galate; 5) butyl galate; 6) pyrocatehol. for less than one minute, whereas in the vicinity of the equivalence point for about 1-2 min. The results of the determinations, given in Table 3 , showed that at $5 \mathrm{~mA}$ the oxidation proceeded with $99.8-100.1 \%$ current efficiency with good reproducibility. At a current higher than $5 \mathrm{~mA}$, the oxidation was not quantitatively and proceeded with a current efficiency of less than $99 \%$. These results are similar with results presented in the papers by Vajgand et al. . $^{3,42,46}$ which show that the hydrogen ions obtained by coulometry is successfully apllied for determination of weak bases. Furthermore, the results obtained in the determination of the bases using pyrite indicator electrode (Table 3) deviated on average by $0.2-0.7 \%$ from those obtained with a glass electrode. It was concluded that the pyrite electrode examined in this research could replace a glass electrode in the titration of bases in the solvents tested.

Table 3. Results of coulometric titrations of bases with hydrogen ions obtained by the oxidation of some organic compounds with potentiometric* end-point detection; $\mathrm{I}=5 \mathrm{~mA}$

\begin{tabular}{lllc}
\hline Solvent & Depolarizer & Titrated base & Recovery $(\%)$ \\
\hline Propionitrile & Pyrocatechol & Tributylamine & $99.9 \pm 0.4$ \\
& & Collidine & $100.1 \pm 0.2$ \\
& 2,2-Bipyridine & $99.9 \pm 0.2$ \\
\multirow{2}{*}{ Ethyl galate } & Tributylamine & $99.9 \pm 0.3$ \\
& & Collidine & $99.8 \pm 0.4$ \\
& 2,2-Bipyridine & $99.9 \pm 0.3$ \\
& & Tributylamine & $100.0 \pm 0.3$ \\
& Collidine & $100.1 \pm 0.3$ \\
& 2,2-Bipyridine & $100.0 \pm 0.2$ \\
& Dodecyl galate & Tributylamine & $99.9 \pm 0.7$ \\
& & Collidine & $100.0 \pm 0.6$ \\
& 2,2-Bipyridine & $100.1 \pm 0.3$ \\
\hline
\end{tabular}

$* \mathrm{FeS}_{2}$-SCE.

\section{Conclusions}

The natural minerals pyrite and chalcopyrite, were used as the indicator electrode sensors for the determinations of some organic acids and bases in acetonitrile and propionitrile as solvents. Based on the results it may be concluded that the natural minerals pyrite and chalcopyrite can be successfully applied as indicator electrodes in such determinations. The potential during the titration and at the equivalence point were rapidly established. The sensors carrier are pyrite and chalcopyrite, the monocrystallines, which are chemically inert in all working mediums, so these electrodes are very suitable for such determinations. Therefore, the proposed electrodes can be a good alternative for a glass electrode in the investigated solvents. 
Additionally, the use of the $m$-dihydroxybenzene, some gallic acid esters, $m$-cresol and 3-methoxy phenol as a source of hydrogen and lyate ions in the determination of acids and bases in acetonitrile and propionitrile as solvents, make it simpler than the classical potentiometric method. By means of this procedure the use of a standard acid (base) solution is avoided, and according to application of the depolarizers brings no foreign organic compounds into the solution being investigated.

\section{Acknowledgment}

This work is supported by the Ministry of Science and Technological Development of the Republic of Serbia (Project No. 172 036).

\section{References}

1. Hanselman, R. B.; Streuli, C. A.; Anal. Chem. 1956, 28, 916.

2. Vajgand, V.; Mihajlović, R.; Mihajlović, Lj.; Joksimović, V.; Anal. Chim. Acta 1988, 212, 73.

3. Mihajlović, R.; Vajgand, V.; Jaksić, Lj.; Manetović, M.; Anal. Chim. Acta 1990, 229, 287.

4. Mihajlović, R.; Vajgand, V.; Talanta 1983, 30, 789.

5. Mihajlović, R.; Mihajlović, Lj.; Vajgand, V.; Jakšić, Lj.; Talanta 1989, 36, 1135.

6. Mihajlović, R.; Vajgand, V.; Simić, Z.; Anal. Chim. Acta 1992 , 265,35 .

7. Mihajlović, R.; Simić, Z.; Mihajlović, Lj.; Jokić, A.; Vukašinović, M.; Rakićević, N.; Anal. Chim. Acta 1996, 318 , 287.

8. Cooksey, B. G.; Metters, B.; Ottaway, J. M.; Whymark, D. W.; Talanta 1973, 20, 371.

9. Bos, M.; Dahmen, E. A. M. F.; Anal. Chim. Acta 1974, 72, 169, 345.

10. Bos, M.; Ijpma, S. T.; Dahmen, E. A. M. F.; Anal. Chim. Acta 1976, 83, 39.

11. Streuli, C. A.; Cincotta, J. J.; Mariele, D. L.; Mead, K. K.; Anal. Chem. 1964, 36, 1371.

12. Fritz, J. S.; Gainer, E. F.; Talanta 1968, 15, 939.

13. Johansson, G.; Talanta 1964, 11, 789.

14. Greenhow, E. J.; Al-Mudarris, B. F.; Talanta 1975, 22, 417.

15. Doležal, J.; Štulik, K.; J. Electroanal. Chem. 1968, 17, 87.

16. Park, S.; Boo, H.; Kim, Y.; Han, J. H.; Kim, H. C.; Dong, T.; Anal. Chem. 2005, 77, 7695.

17. Olthuis, W.; Bomer, J. G.; Bergveld, P.; Bos, M.; van der Linden, W.E.; Sens. Actuators, B 1991, 5, 47.

18. Einerhand, R. E. F.; Visscher, W. H. M.; Barendrecht, E.; Electrochim. Acta 1989, 34, 345.

19. Antonijević, M. M.; Mihajlović, R. P.; Vukanović, B. V.; Jovanović, S.; Analysis 1997, 25, 152.
20. Warren, G. W.; Wadsworth, M. E.; El-Raghy, S.M.; Metall. Trans. B: Process Metall. 1982, 13, 571.

21. Pashkov, G. L.; Mikhlina, E. V.; Kholmogorov, A. G.; Mikhlin, Y. L.; Hydrometallurgy 2002, 63, 171.

22. Mihajlović, R. P.; Stanić, Z. D.; J. Solid State Electrochem. 2005, 9,558.

23. Mihajlović, R.; Stanić, Z.; J. Solid State Electrochem. 2005, 9 , 558.

24. Mihajlović, Lj.; Mihajlović, R.; Antonijević, M.; Vukanović, B.; Talanta 2004, 64, 879.

25. Gomez, C.; Figureoa, M.; Munoz, J.; Blazguez, M. L.; Ballester, A.; Hydrometallurgy 1996, 56, 145.

26. Lu, Z. Y.; Jeffrey, M. I.; Lawson, F.; Hydometallurgy 2000, 56, 189.

27. Elsherief, A. E.; Miner. Eng. 2002, 15, 215.

28. Antonijević, M. M.; Mihajlović, R. P.; Vukanović, B. V.; Jovanović, S.; Analysis 1997, 25, 152.

29. Mihajlović, R.; Stanić, Z.; Antonijević, M.; Electrochim. Acta 2006, 51, 3707.

30. Denesh, M.; Titrovanie v Nevodnykh Rastvorakh, Mir: Moscow, 1971.

31. Kreshkov, P.; Bykova, N.; Kazaryan, A.; Kislotno-Osnovnoe Titrovanie v Nevodnykh Rastvorakh (Acid-Base Titrations in Non-Aqueous Solvents), Khimiya: Moscow, 1967.

32. Gran, G.; Analyst 1952, 77, 661.

33. Antonijević, M. M.; Mihajlović, R. P.; Vukanović, B. V.; J. Solid State Electrochem. 2001, 5, 29.

34. Pikna, L.; Lux, L.; Grygar, T.; Chem. Pap. 2006, 60, 293.

35. Hiroyoshi, N.; Kuroiwa, S.; Miki, H.; Tsunekawa, M.; Hirajima, T.; Hydrometallurgy 2004, 74, 103.

36. Arce, M. E.; Gonzàles, I.; Int. J. Miner. Process. 2002, 67, 17.

37. Antonijević, M. M.; Bogdanović, G. D.; Hydrometalurgy 2004 , 73,245 .

38. Hackl, R. P.; Dreisinger, D. B.; Peters, E.; King, J. A.; Hydrometalurgy 1995, 39, 25.

39. Streuli, C. A.; Cincinota, J. J.; Maricle, D. L.; Mead, K. K.; Anal. Chem. 1964, 36, 1371.

40. Champion, C. E.; Bush, D. G.; Anal. Chem. 1973, 45, 640.

41. Mihajlović, R.; Stanić, Z.; Antonijević, M.; Anal. Chim. Acta 2003, 497, 143.

42. Mihajlović, R. P.; Vajgand, V. J.; Manetović, M. S.; J. Serb. Chem. Soc. 1991, 56, 541.

43. Vajgand, V. J.; Mihajlović, R. P.; Talanta 1969, 16, 1311.

44. Vajgand, V. J.; Mihajlović, R. P.; Anal. Chim. Acta 1983, 152, 275.

45. Jakšić, Lj. N.; Džudović, R. M.; Mihajlović, R. P.; Stanić, Z. D.; J. Serb. Chem. Soc. 2000, 65, 587.

46. Vajgand, V. J.; Mihajlović, R. P.; Manetović, M.; J. Serb. Chem. Soc. 1984, 49, 621 .

Submitted: March 1, 2010

Published online: January 18, 2011 